\title{
Análise do impacto do período de projeto de pavimentos no custo global de obras rodoviárias
}

\author{
Luiz Guilherme Rodrigues de Mello ${ }^{1}$, Márcio Muniz de Farias², Ernesto Simões Preussler ${ }^{3}$ e Rodrigo Preussler ${ }^{4}$
}

\begin{abstract}
Resumo: O projeto de grandes empreendimentos em rodovias federais baseia-se nas metodologias tradicionais de dimensionamento de pavimentos. A prática usualmente adotada pelos projetistas de pavimentos flexíveis está fortemente associada ao período de projeto de 10 anos. Porém, alguns empreendimentos rodoviários são muito caros e os custos de implantação considerando o volume de movimentação de terra ou a existência de grandes obras-de-arte especiais faz com que a parcela relativa ao pavimento não seja significativa. Nesse contexto, torna-se importante conhecer o impacto no custo global de um empreendimento considerando a variação do período de projeto de pavimentos. Essa informação pode auxiliar, ainda quando da fase de estudo de viabilidade técnica. O presente trabalho procura demonstrar o impacto do custo em alguns empreendimentos de grande porte em função do aumento do horizonte de projetos de pavimentos rodoviários. Para isso foram selecionados 5 obras que o DNIT está executando no âmbito do Programa de Aceleração do Crescimento - PAC. De acordo com os resultados, um aumento significativo do período de projeto não se reflete em grandes incrementos nos custos totais dos empreendimentos. Esses resultados demonstram que, ainda na fase de estudo de viabilidade, pode-se avaliar a oportunidade de considerar estudos com projetos longevos para pavimentos rodoviários sem que os custos sejam impactados fortemente.

Palavras-chave: período de projeto, confiabilidade, pavimento, custo de projeto.
\end{abstract} Abstract: Most projects for the construction of big highways in Brazil are based on conventional design methods. It is also
common practice in Brazil to adopt a period of ten years to account for the traffic load when designing flexible pavements.
However, some highway infrastructure projects are rather expensive and the costs related to earthworks or special structures,
such as bridges and drainage, can significantly overshadow the cost of the pavement construction. Therefore, it is important
to evaluate the economic impact of considering longer design periods, still in the stage of study of viability of a big highway
project. The objective of this paper is to show the relation between overall cost and design reliability with the increase of
design period. Five big highways infrastructure projects under construction by the Brazilian National Department of
Transport Infrastructure (DNIT), in the context of the Program for Growth Acceleration (PAC), are investigated as case
studies. The cases include two highways with rigid pavement and three others with flexible pavements. The results show
clearly that a significant increase in design period does not impact significantly the overall costs. In all cases, doubling the
period of design would increase the of overall cost of the contract by less than $4 \%$. Perhaps most importantly, the results of
mechanist analyses show that the probability of failure of the pavement due to fatigue cracking of the concrete layer decreases
when longer design periods are adopted. In order works, the adoption of longer design periods not only has little impact on
the overall costs of big highway construction projects, but also lead to pavements with higher design reliability.

Keywords: design period, reliability, pavements, project costs.

\section{INTRODUÇÃO}

Nos últimos 10 anos, a infraestrutura rodoviária brasileira recebeu um volume de investimentos que permitiu que a malha federal fosse recuperada a patamares razoáveis. No ano de 2004, cerca de $47 \%$ da malha rodoviária federal foi classificada como ruim e somente $17 \%$ foi classificada como boa (DNIT, 2015a). Em 2014, a parcela classificada como ruim ficou em $16 \%$, enquanto que $60 \%$ foi classificada como boa. Esse incremento na melhoria das rodovias foi, sem dúvida, função do aumento de investimento público nas rodovias federais, quando então foram investidos

\footnotetext{
${ }^{1}$ Luiz Guilherme Rodrigues de Mello, Departamento Nacional de Infraestrutura, DNIT. (luizguilhermemello@gmail.com)

2 Márcio Muniz de Farias, Departamento de Geotecnia, UnB.

(mmuniz94@gmail.com)

${ }^{3}$ Ernesto Simões Preussler, Dynatest Engenharia Ltda.

(ernesto@dynatest.com.br)

${ }^{4}$ Rodrigo Preussler, Dynatest Engenharia Ltda.

(rodrigo@dynatest.com.br)
}

Manuscrito recebido em 07/01/2016 e aprovado para publicação em 14/04/2016. cerca de $\mathrm{R} \$ 30$ bilhões em manutenção de rodovias entre 2005 e 2014.

Os investimentos não se concentraram apenas na manutenção da malha, mas também na implantação e duplicação de rodovias, cujos investimentos somaram mais de $\mathrm{R} \$ 35$ bilhões no mesmo período. Enquanto recentes concessões transferiram parte da malha federal para a iniciativa privada, novas rodovias também foram incorporadas. Dessa forma, apesar da transferência de trechos federais ao privado, o Departamento Nacional de Infraestrutura em Transportes - DNIT ainda possui cerca de $52.000 \mathrm{~km}$ de rodovias a serem mantidas e mais de $4.500 \mathrm{~km}$ de rodovias em implantação e duplicação.

Todo o esforço na construção e manutenção das rodovias visa dar ao usuário rodovias seguras e com custo de manutenção reduzido. Para tanto, esse objetivo passa obrigatoriamente pelo desenvolvimento de projetos adequados, execução de acordo com as especificações e o respeito às tolerâncias do peso por eixo nos veículos de carga. $\mathrm{O}$ atual cenário dos projetos de pavimentos rodoviários brasileiros, principalmente aqueles referentes a rodovias ainda não concedidas para a iniciativa privada, está fortemente ligado às diretrizes existentes nos manuais do DNIT. 
Tabela 1. Exemplo de períodos de projeto de pavimentos rodoviários em alguns países

\begin{tabular}{|c|c|c|c|}
\hline País/Estado & Período de Projeto & Observação & Referência \\
\hline EUA/Havaí & 20 a 50 anos & Variável com o volume de tráfego & (HIDOT, 2002) \\
\hline EUA/Illinois & 20 anos & & (IDOT, 2015) \\
\hline EUA/Colorado & 20 anos para flexível e 30 anos para rígido & & (CODOT, 2015) \\
\hline EUA/Flórida & 20 anos & $\begin{array}{l}\text { Para recapeamento (flexível) pode va- } \\
\text { rias de } 8 \text { a } 20 \text { anos }\end{array}$ & (FDOT, 2015) \\
\hline EUA/Carolina do Sul & 20 anos para flexível e 30 anos para rígido & $\begin{array}{l}\text { Pavimento flexível utilizando misturas } \\
\text { Superpave }\end{array}$ & (SCDOT, 2008) \\
\hline EUA/Michigan & 20 anos & & (MDOT, 2012) \\
\hline $\begin{array}{l}\text { Inglaterra/Kent } \\
\text { Country }\end{array}$ & 20 anos & & $(\mathrm{KCC}, 2001)$ \\
\hline Alemanha & 30 anos para rígido & & (Hall et al., 2007) \\
\hline Bélgica & 30 anos para rígido & & (Hall et al., 2007) \\
\hline Canadá/Quebec & 30 anos para rígido & & (Hall et al., 2007) \\
\hline EUA/Texas & 20 anos para flexível e 30 anos para rígido & & (TXDOT, 2011) \\
\hline
\end{tabular}

Oriundo do então DNER (Departamento Nacional de Estradas de Rodagem), o DNIT ainda utiliza metodologias atualmente pouco efetivas, tais como o método Murilo Lopes de Souza (DNIT, 2006). Essa metodologia, apesar de ter sido amplamente utilizada durante um longo período, apresenta-se obsoleta considerando a existência de técnicas e metodologias mais modernas, tais como as análises baseadas em conceitos mecanicistas (Santiago e Soares, 2105; Medina e Motta, 2015). Além disso, o grande crescimento do tráfego nas rodovias nos últimos anos também requer a utilização de conceitos baseados no desempenho dos pavimentos. Segundo o DENATRAN (2015) a frota de ônibus e caminhões cresceu mais de $1.000 \%$ entre 1970 e 2015.

Apesar do esforço realizado por diversos setores da academia no Brasil, como a Rede Temática do Asfalto e o trabalho desenvolvido por FRANCO (2007), e, por outro lado, considerando o reduzido esforço realizado pelo Governo Federal nos últimos anos, quando então o Instituto de Pesquisa Rodoviárias (IPR) recebeu investimentos aquém do desejado, ainda não há uma metodologia oficial que utilize conceitos mecanicistas amplamente adotada no país. Essa lacuna faz com que os projetos desenvolvidos atualmente ainda utilizem metodologias ultrapassadas. É oportuno destacar, contudo, que uma versão do novo método de dimensionamento mecanístico está em fase de teste pela Rede Temática do Asfalto e em vias de ser implementado.

Mesmo não sendo uma imposição normativa, o dimensionamento de projetos de pavimentos rodoviários tem sido limitado a um período de 10 anos, no caso de pavimentos flexíveis ou semi-rígidos. Já para pavimentos rígidos, tem sido uma tendência nacional a definição de 20 anos para o horizonte de projeto. A título de comparação, o Departamento de Estradas do Estado da Califórnia (Caltrans) define o prazo mínimo de 20 ou 40 anos para novas construções ou reconstruções, dependendo do nível do tráfego que a rodovia irá experimentar (HDM, 2015). A Tabela 1 ilustra outros exemplos de períodos de dimensionamento.

O limite temporal definido pelos projetistas está diretamente ligado aos estudos de viabilidade econômica e ambiental realizados antes do início do projeto. Naquele momento, portanto, definem-se cenários que irão fornecer diretrizes para a concepção do projeto. Entretanto, algumas diretrizes podem mudar ainda na fase do estudo de viabilidade caso a informação da variabilidade do custo de um projeto de pavimento seja conhecida, alternando-se o horizonte da vida útil do pavimento ainda que de forma preli- minar. Nesse contexto, seria de extrema valia o conhecimento do impacto relativo dos custos de um projeto de pavimento para diferentes cenários de vida útil. Tais informações poderiam auxiliar, ainda na fase preliminar de um projeto, a definição da diretriz mais adequada e eficiente para um determinado projeto considerando as intervenções futuras.

Os métodos usualmente utilizados, como o método baseado no CBR originalmente desenvolvido pela AASHTO, possuem fundamentações empíricas relevantes e não levam em consideração informações importantes, tais como o comportamento de novos materiais, a influência de novos tipos de carregamento existentes, bem como não analisam o comportamento à fadiga e o afundamento plástico da camada de revestimento asfáltico.

Projetos de pavimentos flexíveis com vida útil de 10 anos, executados de acordo com as especificações e com a atuação dos esforços esperados, iniciam o processo de degradação antes do prazo definido em projeto. Por exemplo, o Asphalt Institute (AI, 1999) propõe a calibração do modelo de ruptura por fadiga em revestimentos asfálticos quando o pavimento apresenta $20 \%$ de sua área fissurada. Portanto, antes dos 10 anos, caso a manutenção não seja adequada, os usuários poderão perceber defeitos no pavimento. Considerando, ainda, o lapso temporal entre os levantamentos realizados no projeto e o término da execução do pavimento, prazo esse que reduz o período em que a rodovia encontra-se em operação, não seria difícil imaginar que pavimentos recém construídos e abertos ao tráfego apresentem ruptura muito antes do prazo esperado.

Esse fenômeno, aos olhos dos usuários e da mídia, permite interpretações às vezes equivocadas de que o pavimento foi mal executado ou que os materiais escolhidos são de baixa qualidade. Na verdade, trata-se de um processo esperado, ou seja, seria incomum se o pavimento não se comportasse da maneira pela qual foi projetado. Isso sem considerar que os projetos são desenvolvidos considerando conceitos determinísticos, sem o uso de critérios estatísticos, o que pode acarretar, na prática, vida útil inferior ao valor determinístico considerado originalmente (SANTOS, 2011).

Em grandes empreendimentos rodoviários, a escolha da vida útil de um projeto de pavimento deve ter atenção especial. Alguns deles levam anos para serem finalizados em função dos diferentes tipos de entraves que obras públicas enfrentam, tais como desapropriação, problemas ambientais e de projeto. 


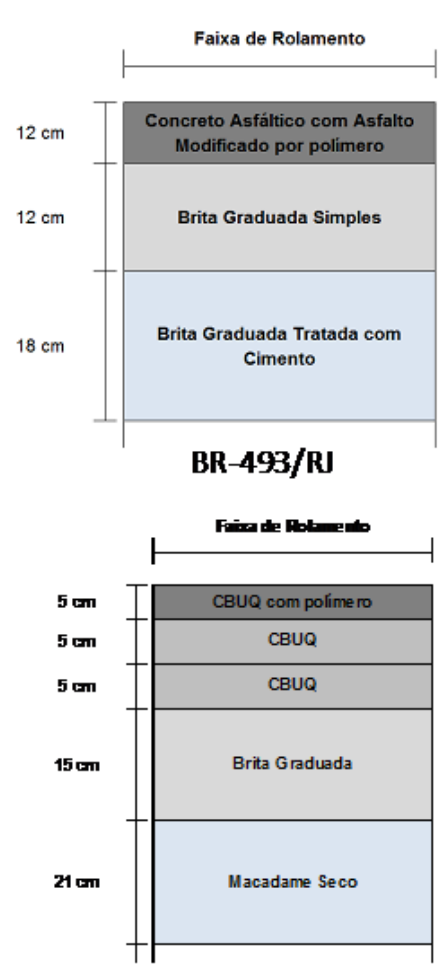

BR-116/RS
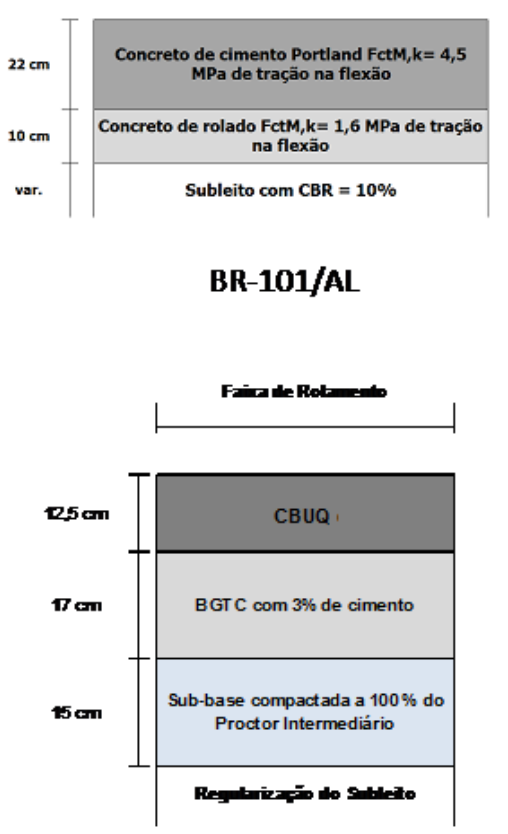

BR-381/MG

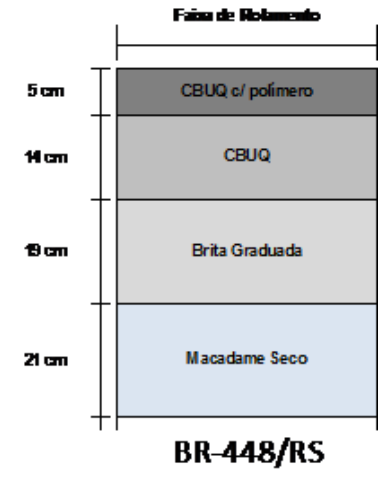

BR-448/RS

Figura 1. Detalhes das estruturas dos pavimentos das rodovias BR-493/RJ, BR-101/AL, BR-448/RS, BR-116/RS e BR-381/MG

Diante desses entraves, os pavimentos podem ficar obsoletos com prazos de projeto reduzidos, necessitando intervenções onerosas pouco tempo depois do término completo das obras. Portanto, parece evidente a necessidade de propor mudanças nas concepções dos projetos e estudos de viabilidade econômica relacionados aos projetos de pavimentos rodoviários de grandes empreendimentos, visando maximizar a vida útil projetada, sem onerar, por outro lado, o empreendimento de forma desproporcional.

O trabalho apresenta um resumo das análises efetuadas no âmbito da Diretoria de Infraestrutura Rodoviária com base em relatórios técnicos elaborados em pesquisa contratada pelo DNIT (DNIT, 2015b) e analisados em conjunto com a Universidade de Brasília. Os resultados obtidos puderam fornecer subsídios para que as análises a seguir fossem realizadas, visando avaliar se as premissas atuais dos projetos de pavimentação interferem de forma significativa nos valores globais dos orçamentos dos grandes empreendimentos realizados pelo Governo Federal.

\section{DESCRIÇÃO DOS PROJETOS ESTUDADOS}

Para a realização do presente estudo, foram escolhidos alguns empreendimentos de construção e/ou duplicação de rodovias federais no país executados e em execução, no âmbito do Programa de Aceleração do Crescimento - PAC. A escolha dos empreendimentos se deu, prioritariamente, pelo montante de recursos aplicados ou a aplicar para a conclusão das obras. Grandes obras rodoviárias foram executadas recentemente, sendo que algumas delas encontram-se em operação, enquanto outras estão em fase de execução.

Dentre o leque de opções disponíveis para análise, foram escolhidos empreendimentos com fácil acesso aos dados de projeto. Para ser possível a análise do impacto no custo total do empreendimento, deve-se levar em consideração todos os demais investimentos necessários para a conclusão da obra. Nesse caso, não existe apenas os contratos de execução propriamente ditos, sob responsabilidade das empreiteiras, mas também contratos de supervisão de obras, gerenciamento ambiental, gerenciamento de obras, etc., além dos custos da desapropriação quando existentes. Portanto, o custo total do empreendimento considerado neste trabalho engloba todos esses demais custos que não estão diretamente ligados às atividades de construção. Os empreendimentos escolhidos são as rodovias federias: BR101/AL, BR-493/RJ, BR-448/RS, BR-116/RS e BR381/MG. Os valores dos empreendimentos podem ser obtidos no Portal da Transparência do Governo Federal ou no Portal do Programa de Aceleração do Crescimento - PAC. As estruturas dos pavimentos destas rodovias são apresentadas na Figura 1.

\subsection{Arco Metropolitano do Rio de Janeiro - BR-493/RJ}

O Arco Metropolitano do Rio de Janeiro, BR-493/RJ, desenvolve-se ao longo de aproximadamente $125,0 \mathrm{~km}$, criando a ligação entre a BR-101/RJ ao norte e ao sul. A construção do segmento entre o entroncamento da BR-040/RJ e o trecho sul da BR-101/RJ resultou de uma cooperação do Governo Federal com o Governo Estadual. A implantação se deu em pista dupla ao longo de $72,0 \mathrm{~km}$. O projeto de pavimento teve como horizonte de via útil 10 anos e propôs uma estrutura tipo pavimento invertido, apresentada na Figura 1 (a), com $18 \mathrm{~cm}$ de sub-base em britada graduada tratada com cimento (BGTC), $12 \mathrm{~cm}$ de brita graduada simples (BGS) e $12 \mathrm{~cm}$ de revestimento em concreto betuminoso usinado a quente com asfalto modificado com polímero.

O projeto previu que o ano de abertura ao tráfego seria 2009, com uma taxa média de crescimento do tráfego de 
5,61\% a.a., alcançando em 2018 um número de repetições do eixo padrão, $\mathrm{N}$ (USACE), de 1,71E+08. O empreendimento de implantação da BR-493/RJ, feito em parceria com o Governo do Estado do Rio de Janeiro, custou ao total R\$ 1,97 bilhões, preços atualizados em junho de 2015. Desse montante, pode-se afirmar que cerca de $90 \%$ são valores relativos as obras e os demais $10 \%$ referem-se a desapropriação e licenciamento ambiental. O custo de construção do pavimento representou cerca de $12 \%$ do valor total do empreendimento.

\subsection{Duplicação da rodovia BR-101/AL}

A obra de duplicação da BR-101/AL, em toda sua extensão, utilizou pavimento rígido em sua concepção. Ao longo dos $249,0 \mathrm{~km}$, seis lotes de construção foram contratados para a execução das obras. Ao todo, considerando obras, desapropriação e demais ações para a execução do empreendimento, estão sendo gastos cerca de R \$ 2,24 bilhões. A estrutura do pavimento mostrada na Figura 1 (b) é constituída de $22,0 \mathrm{~cm}$ de placa sobre $10,0 \mathrm{~cm}$ de concreto compactado a rolo e subleito de material granular. $\mathrm{O}$ pavimento foi dimensionado para um horizonte de vida de 20 anos. Estimou-se a abertura ao tráfego em 2012 e o número de repetições do eixo padrão foi de $1,05 \mathrm{E}+08$. A taxa de crescimento prevista foi de $2,50 \%$ a.a.

Considerando a média dos seis lotes de construção da duplicação da rodovia BR-101/AL, o custo de implantação do pavimento da nova pista em pavimento rígido representa cerca de $23 \%$ do valor total do empreendimento.

\subsection{Implantação da rodovia $B R-448 / R S$}

A BR-448/RS foi implantada para ser uma alternativa aos usuários que utilizam a BR-116/RS ao longo da região metropolitana de Porto Alegre. Com uma extensão de cerca de $22 \mathrm{~km}$, a rodovia foi implantada em pista dupla e, por ter atravessado uma região caracterizada por solos de baixa consistência, foram necessárias soluções geotécnicas especiais que encareceram o custo do empreendimento. Além disso, o empreendimento contou com a construção de uma grande obra-de-arte especial, elevando de forma significativa o curto total do empreendimento. Ao todo, a construção da BR-448/RS custou cerca de R \$ 1,37 bilhões, sendo que a implantação da pavimentação custou R \$ 102,00 milhões, ou seja, cerca $7 \%$ referente ao empreendimento total. Assim como na obra do Arco Metropolitano do Rio de Janeiro, o percentual relativo a construção do pavimento ficou menor em relação aos demais empreendimentos em função das obras-de-arte executadas.

A estrutura de pavimento utilizada nesse empreendimento foi flexível, de acordo com os detalhes da Figura 1 (c), composta por uma camada de $21,0 \mathrm{~cm}$ de macadame seco, 19,0 cm de brita graduada simples (BGS), 19,0 cm de concreto asfáltico. $\mathrm{O}$ dimensionamento considerou um horizonte de 10 anos, com abertura ao tráfego prevista para 2012, para uma taxa de crescimento de 3,00\% a.a. e número $\mathrm{N}$ (USACE) igual a 8,61E+07.

\subsection{Duplicação da rodovia $B R-116 / R S$}

A BR-116/RS está sendo duplicada ao longo de $211 \mathrm{~km}$ e foi dividida em 9 lotes de construção, ligando a capital do Rio Grande do Sul a Pelotas. As soluções adota- das nesta duplicação são usuais e não necessitaram alternativas que produzissem custos elevados. A nova pista foi dimensionada considerando um pavimento flexível, com horizonte de vida útil de 10 anos, taxa de crescimento de $5,00 \%$ a.a. e N (USACE) de 1,2E+08, com previsão de abertura ao tráfego em 2015.

O custo total atual de implantação do empreendimento é de $\mathrm{R} \$ 1,79$ bilhões, sendo que a parcela de implantação do pavimento custa R $\$ 346$ milhões, ou seja, 19\% do total do empreendimento. Neste caso, o custo da implantação do pavimento tornou-se mais representativo em relação ao empreendimento em função das soluções menos onerosas, conforme mencionado anteriormente. Os detalhes da estrutura do pavimento podem ser encontrados na Figura 1 (d), sendo composto por uma sub-base de 21,0 cm de macadame seco, base com $15,0 \mathrm{~cm}$ de brita graduada simples (BGS) e revestimento asfáltico com 15,0 cm.

\subsection{Duplicação da rodovia BR-381/MG}

Esta rodovia é talvez uma das mais perigosas do país. Por atravessar uma região com topografia muito ondulada, a rodovia possui características geométricas que não mais se atendem às demandas atuais. As obras de duplicação e correção de traçado iniciaram em 2013 e encontram-se em andamento. O empreendimento estende-se por $217 \mathrm{~km}$, divididos em oito lotes de construção. Alguns deles foram divididos para facilitar a contratação em função dos altos valores do orçamento. É importante ressaltar que nem todos os lotes possuem solução de duplicação, sendo que alguns deles os serviços previstos possuem apenas adequações em interseções e correções de traçado, incluindo a restauração da pista existente.

Os projetos dos diversos lotes de construção foram realizados por empresas distintas. Por tal motivo, alguns lotes apresentaram soluções de pavimento diferentes, ora em pavimento flexível, ora em pavimento rígido. Para o lote escolhido na análise, o projeto do pavimento foi desenvolvido para um horizonte de 10 anos, com abertura ao tráfego prevista para 2014, taxa de crescimento de $2,5 \%$ a.a. e $\mathrm{N}$ (USACE) de 1,74E+08. Os detalhes da estrutura do pavimento podem ser observados na Figura 1 (e), composto por sub-base compactada a $100 \%$ proctor intermediário, base de brita graduada tratada com cimento com $17,0 \mathrm{~cm}$ e revestimento asfáltico de $12,5 \mathrm{~cm}$. O valor total do empreendimento é de $\mathrm{R} \$ 4,72$ bilhões, sendo $\mathrm{R} \$ 567$ milhões relativos ao pavimento, representando cerca de $12 \%$ do valor do empreendimento.

Pode-se perceber que os cinco empreendimentos descritos apresentaram taxas de crescimento do tráfego distintas como premissa do projeto do pavimento. A taxa depende da região na qual o empreendimento encontra-se, mas também está diretamente ligada à taxa de crescimento econômico do país. Trata-se de um dado que deve ser obtido por meio de um estudo sócio-econômico e pode interferir na espessura do projeto do pavimento.

Para facilitar a análise do impacto no custo do empreendimento com a variabilidade do horizonte do projeto do pavimento, foram resumidas as informações relevantes na Tabela 2. Como pode ser observado, o valor do custo de implantação do pavimento mais representativo em relação ao empreendimento refere-se à obra cujo pavimento é rígido. Outro grande impacto, apesar de ser pavimento flexível, refere-se às obras de duplicação da BR-116/RS. 
MELLO, L.G.R.; FARIAS, M.M.; PREUSSLER, E.S.; PREUSSLER, R.

Tabela 2. Resumo dos valores dos empreendimentos e o impacto do custo da implantação do pavimento.

\begin{tabular}{|c|c|c|c|c|c|}
\hline Rodovia & $\begin{array}{l}\text { Custo total } \\
\text { empreendimento } \\
[\mathrm{R} \$ / \mathrm{US} \$)]^{*}\end{array}$ & $\begin{array}{c}\text { Custo implantação } \\
\text { pavimento } \\
[\mathrm{R} \$ / \mathrm{US} \$)]^{*}\end{array}$ & $\begin{array}{c}\% \\
\text { Relativo }\end{array}$ & $\begin{array}{c}\text { Custo total } \\
\text { por km } \\
{[\mathbf{R} \$ /(\mathbf{U S} \$)]}\end{array}$ & Tipo pavimento \\
\hline BR-493/RJ & $\begin{array}{l}1.966 .634 .115,44 \\
(983.317 .057,50)\end{array}$ & $\begin{array}{c}232.957 .227,78 \\
(116.478 .613,50)\end{array}$ & $12 \%$ & $\begin{array}{c}27.314 .000,0 \\
(13.657 .000,0)\end{array}$ & Invertido e Semi-rígido \\
\hline BR-101/AL & $\begin{array}{l}2.244 .000 .000,00 \\
(1.122 .000 .000,0)\end{array}$ & $\begin{array}{l}526.720 .000,00 \\
(263.360 .000,0)\end{array}$ & $23 \%$ & $\begin{array}{c}9.029 .454,0 \\
(4.514 .727,0)\end{array}$ & Rígido \\
\hline BR-448/RS & $\begin{array}{c}1.370 .000 .000,00 \\
(685.000 .000,0)\end{array}$ & $\begin{array}{c}101.902 .936,59 \\
(50.951 .468,0)\end{array}$ & $7 \%$ & $\begin{array}{c}61.324 .977,0 \\
(30.662 .488,0)\end{array}$ & Flexível \\
\hline BR-116/RS & $\begin{array}{c}1.799 .000 .000,00 \\
(899.500 .000,0)\end{array}$ & $\begin{array}{l}345.905 .104,86 \\
(172.952 .552,0)\end{array}$ & $19 \%$ & $\begin{array}{c}8.751 .064,0 \\
(4.375 .532,0)\end{array}$ & Flexível \\
\hline BR-381/MG & $\begin{array}{l}4.725 .000 .000,00 \\
(2.362 .500 .000,0)\end{array}$ & $\begin{array}{l}567.435 .623,20 \\
(283.717 .811,0)\end{array}$ & $21 \%$ & $\begin{array}{c}15.594 .059 \\
(7.797 .029,0)\end{array}$ & Flexível e Rígido \\
\hline
\end{tabular}

*Taxa de conversão do dólar a $\mathrm{R} \$ 2,00$, valor médio no período de execução das obras.

Nesse caso, como a rodovia possui poucas soluções onerosas, o pavimento passou a ser representativo em relação ao valor global. O menor impacto refere-se à obra cujo pavimento é flexível, cujas intervenções para resolver o problema de geotecnia aliadas às obras-de-arte especiais executadas reduziram o impacto do custo do pavimento no valor total do empreendimento. Os valores apresentados na Tabela 2 demonstram a grande variabilidade do impacto no custo de implantação do pavimento em relação ao valor global do empreendimento, muito em função das peculiaridades das soluções envolvidas em cada obra. Como os empreendimentos estão em fases distintas, os valores apresentados na Tabela 2 referem-se a valores de obras já executadas ou em execução, ou seja, com aditivos e reajustamentos, bem como valores dos orçamentos previstos em obras não iniciadas.

\section{ESTUDO DO IMPACTO NO CUSTO PARA DIFERENTES PERÍODOS DE PROJETO}

Apresentadas as características dos projetos estudados neste trabalho, foram realizadas análises visando determinar quais espessuras das camadas dos pavimentos atendem a períodos de projetos diferentes daqueles originalmente definidos. Além disso, foram determinadas as variações dos custos envolvidos para cada aumento de espessura das camadas do pavimento, observando seu impacto direto em cada lote, ou segmento específico, bem como o impacto total no valor do empreendimento.

\subsection{Análise da variação da espessura do pavimento}

Para realizar o comparativo do impacto no custo do empreendimento em função da variação do período de projeto do pavimento, algumas premissas foram adotadas. Dentre elas, destaca-se a utilização dos mesmos métodos de dimensionamento utilizados nos projetos originais para avaliar as consequências no aumento do prazo de vida útil do pavimento. Além disso, os empreendimentos escolhidos para análise neste trabalho possuem diversos lotes de obra, ou contratos. Para tanto, foi preciso realizar o estudo em um lote representativo para cada empreendimento e, posteriormente, extrapolar os resultados para análise no valor global do empreendimento. A escolha do lote ou contrato representativo se deu em função da proximidade dos valores específicos com aqueles observados em relação à média de todos os demais lotes.

Outra premissa adotada nas análises foi incrementar apenas a espessura da camada de revestimento para atender aos horizontes de projeto propostos. Dessa forma, não foi adotada nenhuma alteração nas espessuras das camadas de base ou sub-base do pavimento, bem como foram mantidas as mesmas características dos materiais propostos nos projetos originais.

A título ilustrativo, considerando as obras de implantação da BR-493/RJ, a análise do impacto no custo global do empreendimento se deu pelo redimensionamento da estrutura do pavimento para atender a diferentes horizontes de vida útil. Assim, considerando a mesma metodologia utilizada em cada projeto, foram feitas análises para verificar qual incremento, por exemplo, atenderia a horizontes de vida útil de 15, 20, 25 e 30 anos para a obra da BR-493/RJ, considerando um dos lotes dos empreendimentos. A escolha do lote a ser analisado se deu pela sua representatividade em relação a todo o empreendimento, ou seja, aquele que possui custo médio mais próximo da média de todos os demais lotes.

Para a determinação do incremento das espessuras do revestimento asfáltico, foram adotadas as mesmas premissas do projeto original. Com isso, foi utilizado a ferramenta ELSYM5, também usada no projeto original, para determinar as tensões e deformações na estrutura do pavimento. Os seguintes modelos de desempenho foram, então, checados para as diferentes camadas, a saber:

$\checkmark \quad$ Modelo do Asphalt Institute, utilizando a deformação horizontal máxima na fibra inferior do revestimento asfáltico para o número $\mathrm{N}$ da AASHTO;

$\checkmark$ Modelo proposto por Ceratti (1991), utilizando a tensão de tração horizontal máxima na fibra inferior da camada cimentada e número $\mathrm{N}$ da USACE;

$\checkmark$ Modelo proposto por Heukelom e Klomp (1962), utilizando a tensão vertical máxima no topo do subleito e o número $\mathrm{N}$ da USACE.

A Figura 2 ilustra o incremento de espessura do revestimento asfáltico para os diferentes horizontes de vida de projeto. Para aumentar a vida útil do pavimento em 5 anos no lote analisado, passando de 10 para 15 anos, necessitaria aumentar a espessura do revestimento asfáltico em apenas $1 \mathrm{~cm}$. Para 20 anos, esse incremento seria de $3,5 \mathrm{~cm}$, e assim por diante. Essa análise permite avaliar, ainda que de forma determinística, variações do projeto do pavimento para diferentes cenários. Essa mesma verificação foi realizada para os demais empreendimentos, respeitando as diretrizes utilizadas no projeto original de cada rodovia. 


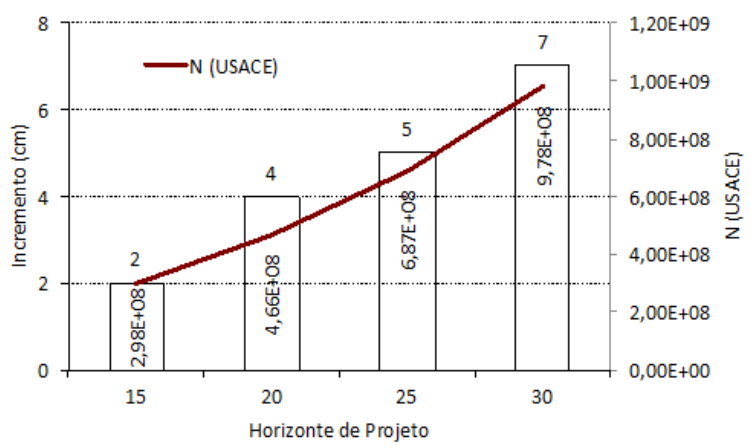

Figura 2. Incremento de espessura do revestimento asfáltico em função da alteração do horizonte de projeto para a BR-493/RJ

Para os empreendimentos que utilizam pavimento flexível, foi adotada uma premissa de elevação do custo de aquisição dos insumos asfálticos à medida que o horizonte de projeto aumentasse. Esse incremento no valor está relacionado à necessária customização do insumo asfáltico para suportar o incremento de cargas no período de projeto. $\mathrm{Ou}$ seja, considerou-se um aumento no custo de aquisição do insumo asfáltico para horizontes de projeto acima de 15 anos tendo em vista a necessidade de obter ligantes com propriedades mecânicas e físicas superiores aos ligantes usualmente utilizados. Optou-se que seriam utilizados, nesses casos, ligantes asfálticos modificados e com custos superiores aos ligantes convencionais. A mudança no valor da aquisição do ligante asfáltico considerou o aumento do valor do insumo em $50 \%$ para 15 e 20 anos e $100 \%$ para 25 e 30 anos.

No caso da BR-101/AL, considerando que o pavimento é rígido, o estudo do impacto no custo em função da variação do horizonte de projeto ficou restrito ao dimensionamento para 30 e 40 anos, tendo em vista que o projeto original definiu prazo de 20 anos. De posse da variação do número $\mathrm{N}$, obteve-se a necessidade de incrementar a espessura do pavimento de acordo com a Figura 3.

O projeto da BR-116/RS foi redimensionado considerando os novos horizontes de vida útil do pavimento, conforme pode ser observado na Figura 4. É importante destacar que esses incrementos de espessura foram adotados apenas na camada de revestimento asfáltico por premissa deste trabalho. Poder-se-ia adotar diferentes formas no redimensionamento, tais como alteração da espessura e/ou tipo dos materiais empregados nas camadas de base e sub-base. Porém, para uniformizar o comparativo, adotou-se como premissa a alteração da camada de revestimento como forma de avaliar o impacto no custo em função da alteração.

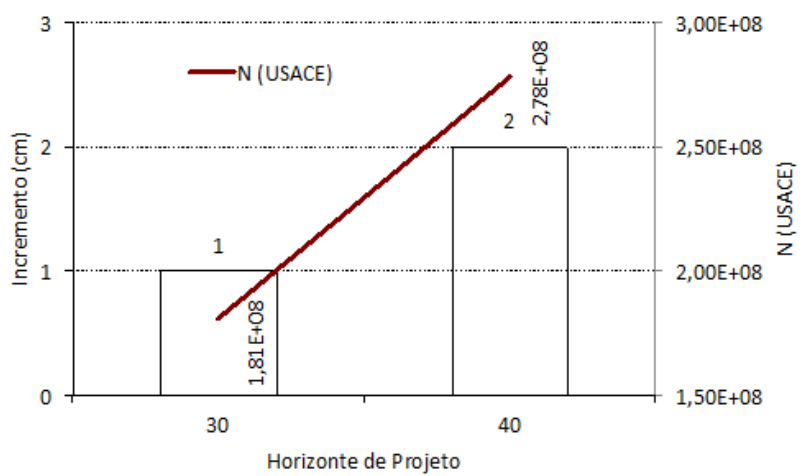

Figura 3. Incremento de espessura da placa de concreto em função da alteração do horizonte de projeto para a BR-101/AL

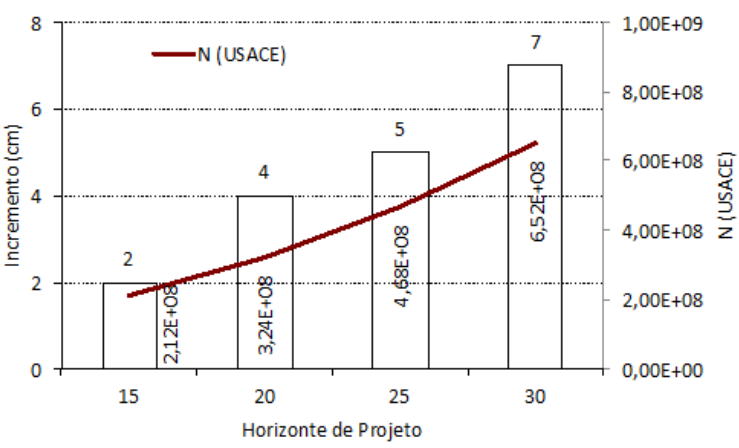

Figura 4. Incremento de espessura do revestimento asfáltico em função da alteração do horizonte de projeto para a BR-116/RS

No caso da BR-448/RS, observou-se uma pequena variação no incremento da espessura do revestimento asfáltico necessária para adequar ao horizonte de 20 e 30 anos (Figura 5). As variações, neste caso específico, ficaram reduzidas muito provavelmente em função do baixo crescimento observado no número $\mathrm{N}$ ao longo dos anos. Em comparação com a BR-116/RS, quando o N passa de 3,24E+08 para 6,52E+08 entre 20 e 30 anos, para a BR-448/RS estima-se um crescimento do número $\mathrm{N}$ de 1,16E+08 para $1,56 \mathrm{E}+08$ no mesmo período. Outro motivo deve-se à metodologia empregada no dimensionamento do projeto original. Como as análises neste trabalho utilizaram a mesma metodologia adotada originalmente, a proposta adotada pode interferir no resultado do incremento da espessura do revestimento asfáltico para diferentes horizontes. Além disso, a própria estrutura do pavimento pode contribuir para justificar esse comportamento distinto entre os dois empreendimentos.

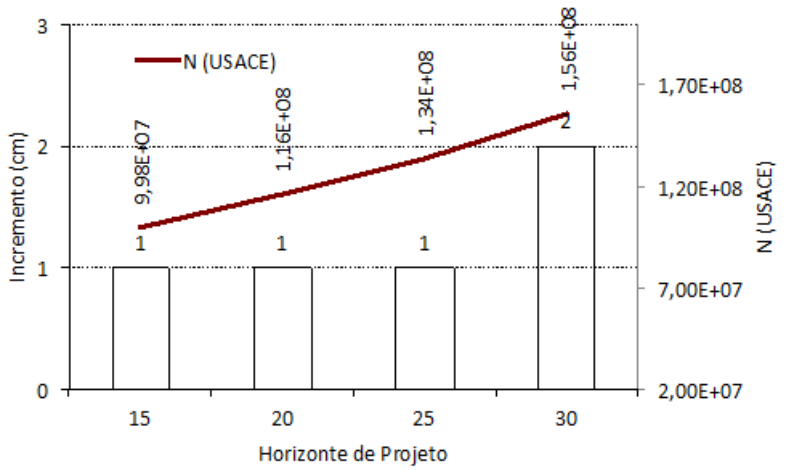

Figura 5. Incremento de espessura do revestimento asfáltico em função do horizonte de projeto para a BR-448/RS

Por último, a Figura 6 apresenta os resultados de incremento da espessura de revestimento asfáltico em função da alteração da alteração do horizonte de vida útil na BR381/MG. Da mesma forma, houve pequenos incrementos de espessura diferentes períodos de projeto. Novamente, o incremento observado para o número $\mathrm{N}$ não é tão representativo quando comparado com, por exemplo a BR-116/RS quando se analisa o interregno entre 20 e 30 anos. No caso da BR-381/MG, o valor de $\mathrm{N}$ passa de 2,23E+08 para $2,85 \mathrm{E}+08$. Outro fator que deve ser considerado, conforme mencionado anteriormente, é o tipo de estrutura do pavimento que está sendo analisado. 


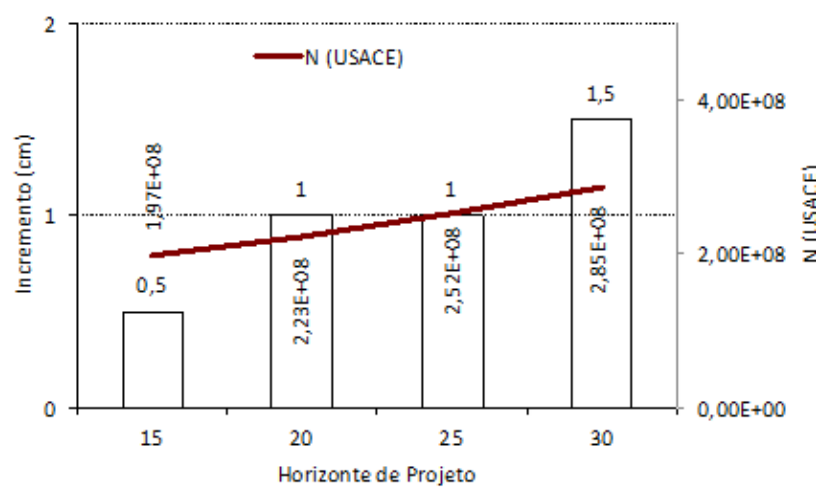

Figura 6. Incremento de espessura do revestimento asfáltico em função da alteração do horizonte de projeto para a BR-381/MG

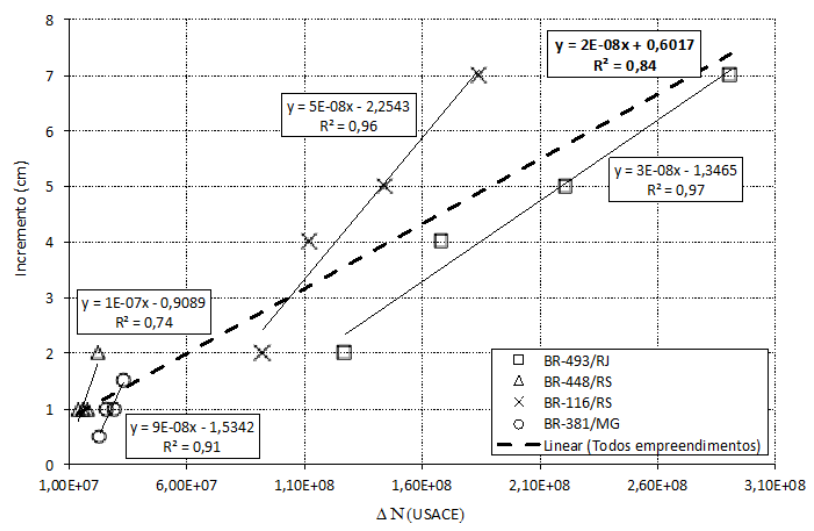

Figura 7. Relação entre incremento da espessura do revestimento asfáltico e a variação do número N (USACE) para diferentes horizontes de projeto, para os empreendimentos BR-493/RJ, BR-381/MG, BR-116/RS e BR-448/RS

Considerando os resultados apresentados, propôs-se a relação apresentada na Figura 7, que demonstra o incremento de espessura observado nos quatro empreendimentos que possuem pavimento com revestimento asfáltico para diferentes horizontes de projeto e a variação do número $\mathrm{N}$ (USACE). Os resultados de todos os quatro empreendimentos considerados, cujos pavimentos possuem revestimento asfáltico, apresentam uma relação linear com bom coeficiente de correlação $\left(R^{2}=0,84\right)$.

Observando, por outro lado, os empreendimentos de forma separada, pode-se constatar que três dos quatro grupos apresentam relação ainda maior de $\mathrm{R}^{2}$, todos acima de 0,90. Além disso, constata-se uma diferenciação nas inclinações das curvas. A taxa do incremento da espessura de revestimento asfáltico dos empreendimentos BR-116/RS, BR-381/MG e BR-448/RS é maior que da BR-493/RJ. Essa diferença pode ser explicada pela característica das estruturas dos pavimentos, bem como pelo método de dimensionamento utilizado no projeto original. A magnitude das deformações de tração na fibra inferior do revestimento é função da rigidez relativa desta camada em relação às camadas inferiores. Deve-se considerar ainda que a rigidez à flexão é influenciada pelo módulo de elasticidade do material vezes o momento de inercia da seção da camada em consideração, que por sua vez depende da espessura da camada. A estrutura do pavimento da BR-493/RJ é composta de um revestimento de $12 \mathrm{~cm}$ em concreto asfáltico modificado com polímero, assentada sob uma rígida camada de $12 \mathrm{~cm}$ BGS e
$18 \mathrm{~cm}$ de BGTC com módulo de 7,0 GPa. Apesar de também possuir uma camada cimentada na estrutura, o projeto do pavimento da BR-381/MG baseou-se no método da resistência (CBR) e com isso o impacto da rigidez não é considerado. Nesse sentido, espera-se que essa estrutura do pavimento da BR-493/RJ tenha menor sensibilidade no cálculo do incremento de espessura do revestimento asfáltico frente a um acréscimo do número $\mathrm{N}$.

\subsection{Análise da variação do custo}

As variações nas espessuras apresentadas no item anterior têm impacto direto no custo de implantação dos empreendimentos. Considerando apenas os valores contratuais, atualizados para o ano de 2015, os impactos nos diferentes empreendimentos são distintos. Conforme mencionado anteriormente, a análise da variação da espessura do pavimento foi feita para um determinado lote representativo do empreendimento como um todo. Esta variação de espessura pode ser representada numa variação do custo de implantação de cada contrato analisado, conforme a Figura 8. Os resultados ilustram que os empreendimentos que possuem maior representatividade do projeto do pavimento no custo global do contrato apresentam maior impacto devido à variação da espessura do pavimento. No caso da BR$116 / \mathrm{RS}$, o pavimento representa uma parcela significativa do empreendimento global e, portanto, demonstra maior sensibilidade quando se observa a variação da espessura do pavimento. Para triplicar o horizonte de projeto, o orçamento de um lote específico teria um incremento de cerca de $20 \%$ no seu custo.

No caso do pavimento rígido (BR-101/AL), como a variação da espessura do pavimento não é significativa, o impacto é reduzido, ou seja, dobrar o horizonte de projeto significa aumentar apenas cerca de $2,0 \%$ o valor de implantação do lote analisado. Para a BR-448/RS, considerando que custo de implantação do pavimento não é representativo, qualquer variação de espessura do pavimento torna-se pouco relevante, ou seja, para triplicar o horizonte de projeto o custo do lote analisado aumentaria cerca de 3,0\%. Importante destacar que foram considerados acréscimos nos custos de aquisição de ligantes asfálticos para períodos de projeto acima de 20 anos, como mencionado anteriormente.

A análise apresentada na Figura 8 ilustra qual o impacto no orçamento de um lote específico considerando o aumento da espessura do pavimento para os diferentes horizontes. Porém, de acordo com o objetivo central do presente trabalho, pretende-se observar qual o impacto do aumento do período de projeto, considerando não apenas um trecho específico, mas todo o empreendimento. Justifica-se essa análise pois o empreendimento contempla não só o custo dos lotes que serão construídos, mas também gastos relativos a desapropriações, serviços de consultorias, etc. Assim, estima-se que qualquer variação no projeto do pavimento teria pouco impacto no valor final do empreendimento, considerando todos os demais gastos. A Tabela 3 apresenta os gastos referentes a um determinado empreendimento (BR-448/RS), contemplando não apenas os valores dos contratos de construção, mas também contratos auxiliares necessários para a execução das obras, tais como desapropriação, licenciamento ambiental, supervisão, gerenciamento, etc. 
Para realizar a análise global, foi feita uma extrapolação do impacto observado no valor dos contratos estudados para todos os demais contratos de execução das obras.

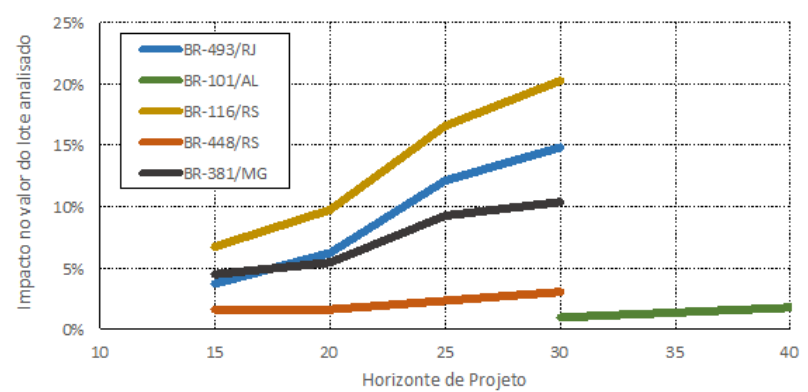

Figura 8. Impacto no orçamento de cada lote analisado em função do aumento do custo do projeto do pavimento para diferentes horizontes de projeto.

Tabela 3. Distribuição dos valores dos contratos que fazem parte do empreendimento BR-448/RS.

\begin{tabular}{lcc}
\hline Item & Valores $(\mathbf{R} \mathbf{\$})$ & $\mathbf{\%}$ \\
\hline Obras principais & $1.120 .337 .615,55$ & $81,7 \%$ \\
Desapropriação & $103.937 .756,69$ & $7,6 \%$ \\
Supervisão & $39.927 .720,73$ & $2,9 \%$ \\
Gerenciamento & $27.579 .672,83$ & $2,0 \%$ \\
Projeto & $5.150 .923,80$ & $0,4 \%$ \\
Obras complementares & $35.800 .000,00$ & $2,6 \%$ \\
Ambiental & $38.172 .126,77$ & $2,8 \%$ \\
TOTAL & $1.370 .905 .816,37$ & \\
\hline
\end{tabular}

A Figura 9 ilustra o resultado da mudança do projeto do pavimento em relação ao valor global do empreendimento. Os números apresentados estão de acordo com a expectativa esperada neste trabalho. O impacto gerado no custo global do empreendimento, considerando todos os gastos necessários para sua realização, foi menor que 5,0\% em todos os casos. Para a BR-116/RS, obra que gera o maior impacto, triplicar o horizonte do projeto do pavimento, passando de 10 para 30 anos, representa aumentar 4,0\% do empreendimento. Já para a BR-381/MG, o impacto de triplicar a vida útil do projeto chegou a $1,25 \%$. No caso das rodovias BR-101/AL e BR-448/RS o impacto ficou menor que $1,0 \%$.

Esses resultados procuram demonstrar que os estudos de viabilidade econômica dos empreendimentos devem levar em consideração tais variações num cenário macro, ou seja, considerando todos os demais custos envolvidos na realização de um grande empreendimento, bem como considerar as características inerentes das obras. Construções que possuem grandes movimentos de terraplenagem ou maior número de obras-de-arte especiais tendem a sofrer menor impacto no orçamento final do empreendimento com a variação do período de projeto de pavimentos.

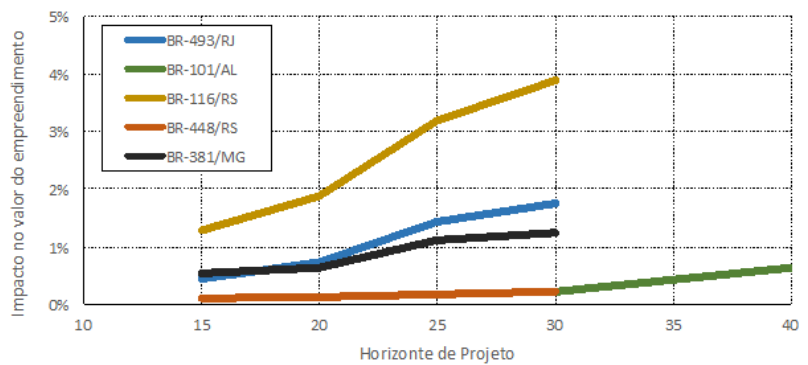

Figura 9. Impacto no custo global do empreendimento em função da alteração do horizonte de projeto.

\section{CONFIABILIDADE DO PROJETO DO PAVIMENTO EM FUNÇÃO DO PERÍODO DE PROJETO}

Mais do que analisar o impacto no custo do projeto de um pavimento, é importante observar qual a consequência em adotar diferentes períodos de projeto no comportamento da estrutura do pavimento. Para isso, procurou-se avaliar quais resultados seriam obtidos se a premissa determinística adotada nos projetos aqui analisados fosse alterada, considerando a variabilidade de parâmetros que interferem no dimensionamento. Assim, valores antes determinísticos num dimensionamento são considerados variáveis, tais como CBR e espessura de camadas do pavimento que, sabidamente, podem variar em campo como demonstrado por Borges et al. (2014) e Silva (2014).

No presente trabalho procurou-se avaliar um empreendimento com pavimento flexível, no caso a BR-493/RJ, e o pavimento rígido da BR-101/AL. Inicialmente, definiu-se quais variáveis teriam seus parâmetros relativizados. Para a BR-493/RJ escolheu-se as espessuras da sub-base, base e revestimento asfáltico, bem como os valores do CBR do subleito e os módulos de resiliência de cada camada. As distribuições estatísticas desses parâmetros, tais como coeficiente de variação e desvio padrão, seguiram os resultados observados em literatura (TIMM et al., 1999; HUANG, 2004; SANTOS, 2011). A título de exemplo, a Tabela 4 apresenta os valores médios, mínimos e máximos para os módulos de resiliência das camadas de revestimento asfáltico, base e sub-base utilizados no projeto original.

Para avaliar o comportamento da estrutura do pavimento considerando todas as variabilidades possíveis, empregou-se a método Monte Carlo, considerando um erro máximo de 2,0\%. A variável dependente analisada no caso da BR-493/RJ foi a deformação de tração na fibra inferior do revestimento asfáltico para fins de análise da vida de fadiga. Para esse cenário, foram simuladas 5.000 estruturas com diferentes configurações, utilizando o programa ELSYM5 para a determinação das tensões e deformações atuantes no pavimento. Com base nestas deformações foi calculado o número de repetições do eixo padrão que levaria à ruína do pavimento por fadiga da camada de revestimento $\left(\mathrm{N}_{\mathrm{f}}\right)$. Considerou-se que o pavimento tinha possibilidade de ruína precoce, caso o consumo de fadiga, dado pela relação entre o número de repetições do eixo padrão previstas no período de projeto $\left(\mathrm{N}_{\mathrm{p}}\right)$ e o $\mathrm{N}_{\mathrm{f}}$, fosse igual ou superior a um $\left(\mathrm{N}_{\mathrm{p}} / \mathrm{N}_{\mathrm{f}} \geq 1,0\right)$.

Tabela 4. Valores estatísticos do módulo de resiliência das camadas do pavimento da BR-493/RJ.

\begin{tabular}{llll}
\hline Material & $\begin{array}{l}\text { Mr Médio } \\
\text { (Mpa) }\end{array}$ & $\begin{array}{l}\text { Mr Mínimo } \\
\text { (Mpa) }\end{array}$ & $\begin{array}{l}\text { Mr Máximo } \\
\text { (Mpa) }\end{array}$ \\
\hline CBUQ & $3.750,00$ & $3.000,00$ & $4.500,00$ \\
BGS & 300,00 & 240,00 & 360,00 \\
BGTC & $7.000,00$ & $5.600,00$ & $8.400,00$ \\
\hline
\end{tabular}

Para o caso da BR-493/RJ o projeto original considerou o uso do critério de ruptura a fadiga da camada de revestimento asfáltico proposto pelo Asphalt Institute (AI, 1999). Apesar da limitação na utilização do modelo do AI nas condições brasileiras, não foram feitas críticas em relação aos modelos utilizados nos projetos originais, apenas foram adotados os mesmos embasamentos utilizados pelos projetistas, conforme mencionado anteriormente. 
Não foi feita a análise do comportamento da camada cimentada da sub-base em função dessa não ter sido considerada crítica no projeto original.

Considerando as análises para o horizonte de 10 anos (Figura 10), apenas 51,2\% dos 5000 casos analisados atendem ao período de projeto. Ou seja, mesmo considerando a adoção das premissas normativas do DNIT, um número considerável $(48,8 \%)$ de casos analisados apresentaria consumo total de fadiga do revestimento antes do período de projeto de 10 anos. Nesse mesmo caso, aos 5 anos de operação observa-se que $31,9 \%$ dos casos analisados atingiram o limite de fadiga $(\mathrm{Np} / \mathrm{Nf}>1,0)$, ou seja, 1 em cada 3 pavimentos construídos poderiam atingir uma fadiga precoce em menos de 5 anos de vida. $\mathrm{O}$ aumento de $1,0 \mathrm{~cm}$ na espessura do revestimento asfáltico, com horizonte de 15 anos, resulta numa queda para $19,1 \%$ de casos que atingiriam o limite de fadiga até o décimo ano de operação. Ou seja, considerar o horizonte de 15 anos no dimensionamento resulta numa queda drástica na possibilidade de fadiga precoce para o prazo de 10 anos.

No caso do horizonte de projeto de 20 anos, o acréscimo de $3,5 \mathrm{~cm}$ de espessura de revestimento reduz o número de casos de fadiga precoce em 10 anos para apenas $0,5 \%$. Esse incremento na espessura do revestimento para alcançar, na forma determinística, 20 anos no horizonte de projeto representa um incremento de apenas $1,0 \%$ no custo global do empreendimento (Figura 9). São apresentadas, ainda, as simulações para os horizontes de 25 e 30 anos.

Este tipo de análise permite observar qual horizonte de projeto deva ser utilizado num dimensionamento para que se tenha, por exemplo, no máximo 5,0\% dos casos apresentando ruptura pré-matura. A Figura 11 apresenta essa análise para a BR-493/RJ, considerando o limite de 5,0\% dos casos apresentando ruptura precoce pelo modelo de desempenho adotado e a variabilidade dos parâmetros adotada.

O exemplo indicado na figura demonstra que para atingir o limite de 5,0\% de ruptura num prazo de 10 anos, deve-se realizar o dimensionamento para um horizonte de projeto de 18 anos e para atingir este limite de 5\% num prazo de 20 anos, deve-se projetar o pavimento com um horizonte de 25 anos.

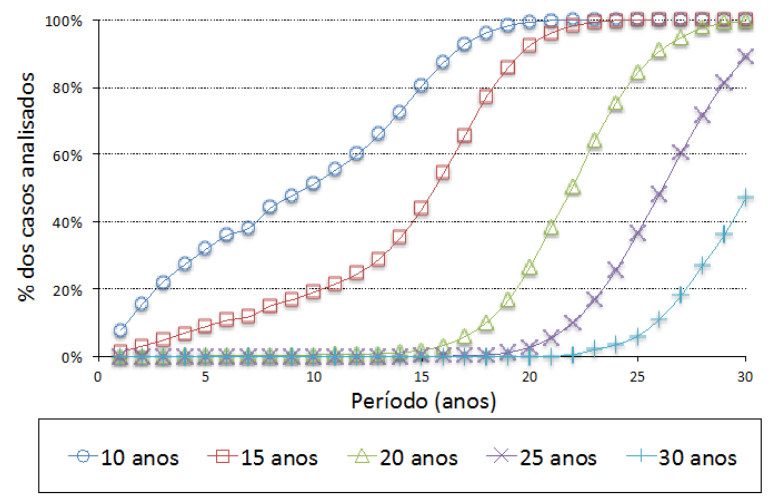

Figura 10. Porcentagem de casos com consumo de fadiga precoce para períodos de projeto 10,15,20,25 e 30 anos - Caso da BR-493/RJ.

O mesmo estudo de confiabilidade em função do horizonte de projeto foi realizado para o pavimento rígido da BR-101/AL. Nesse caso, as variáveis selecionadas para o tratamento estatísticos foram o CBR do subleito, a espessura da placa de concreto e a resistência à tração na flexão do concreto, critério definido no dimensionamento e que pode variar em campo.

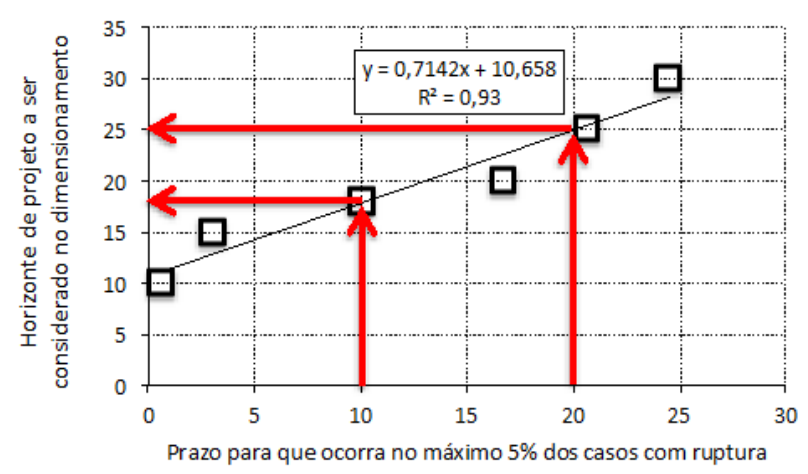

Figura 11. Relação entre o prazo para que ocorra no máximo $5,0 \%$ dos casos com ruptura e o horizonte de projeto a ser utilizado no dimensionamento do pavimento.

A variável dependente de análise, nesse projeto, foi o percentual de consumo da vida de fadiga considerado no método de dimensionamento, diretamente relacionado à tensão de tração desenvolvida na fibra inferior da placa de concreto. No caso do pavimento rígido, foram simuladas estruturas do pavimento com placas de concreto de 27,28 e $29 \mathrm{~cm}$, espessuras essas que são resultados obtidos antes de adotar a redução em função da aplicação da sub-base em CCR, de acordo com o método de dimensionamento da Portland Cement Association - PCA (HUANG, 2004), como pode ser observado na Tabela 5.

Outra forma de apresentar os resultados é avaliar a redução do número de casos com fadiga precoce para o tráfego de projeto, ou seja, 20 anos, considerando o incremento de espessura do pavimento. Pela Figura 12 pode-se perceber que a análise considerando a variabilidade de parâmetros no dimensionamento de pavimentos rígidos indica que $32 \%$ dos casos teriam consumo de fadiga superior a $100 \%$. Ou seja, mesmo realizando o dimensionamento para um determinado tráfego para 20 anos, somente $68 \%$ dos casos analisados apresentariam um consumo de fadiga inferior a $100 \%$.

Tabela 5. Equivalência entre estruturas de pavimento rígido em função do uso do CCR.

\begin{tabular}{ccc}
\hline $\begin{array}{c}\text { Horizonte de } \\
\text { projeto }\end{array}$ & $\begin{array}{c}\text { Espessura de } \\
\text { placa }\end{array}$ & $\begin{array}{c}\text { Estrutura } \\
\text { combinada }\end{array}$ \\
\hline 20 & $27 \mathrm{~cm}$ de placa & $\begin{array}{c}10 \mathrm{~cm} \mathrm{de} \mathrm{CCR}+ \\
22 \mathrm{~cm} \text { de placa }\end{array}$ \\
& $28 \mathrm{~cm}$ de placa & $\begin{array}{c}10 \mathrm{~cm} \text { de CCR }+ \\
23 \mathrm{~cm} \text { de placa }\end{array}$ \\
30 & $29 \mathrm{~cm}$ de placa & $\begin{array}{c}10 \mathrm{~cm} \text { de CCR }+ \\
24 \mathrm{~cm} \text { de placa }\end{array}$ \\
\hline
\end{tabular}

Aumentando a espessura da placa em $1,0 \mathrm{~cm}$, o que representaria um período de projeto de 30 anos, cerca de $12 \%$ dos casos analisados teriam consumo de fadiga superior a $100 \%$ no intervalo de 20 anos. Para um horizonte de 40 anos, ou seja, aumentando a espessura em $2 \mathrm{~cm}$, somente $3 \%$ dos casos apresentam consumo de fadiga superior a $100 \%$ no intervalo de 20 anos. Essa variabilidade demonstra 
que para o impacto financeiro de menos de $1,0 \%$ no empreendimento global para um acréscimo de $2,0 \mathrm{~cm}$ da placa de concreto, obtêm-se uma redução de casos com fadiga precoce de $32 \%$ para apenas $3 \%$ num intervalo de 20 anos de uso.

Este tipo de análise ilustra o impacto do aumento do horizonte de projeto de pavimentos no orçamento de grandes empreendimentos, cujos custos não são apenas aqueles relativos às obras. Além disso, a depender da característica do empreendimento, o custo do pavimento é diluído frente a representatividade de outros serviços, reduzindo ainda mais o impacto no custo em função do aumento do horizonte de projetos.

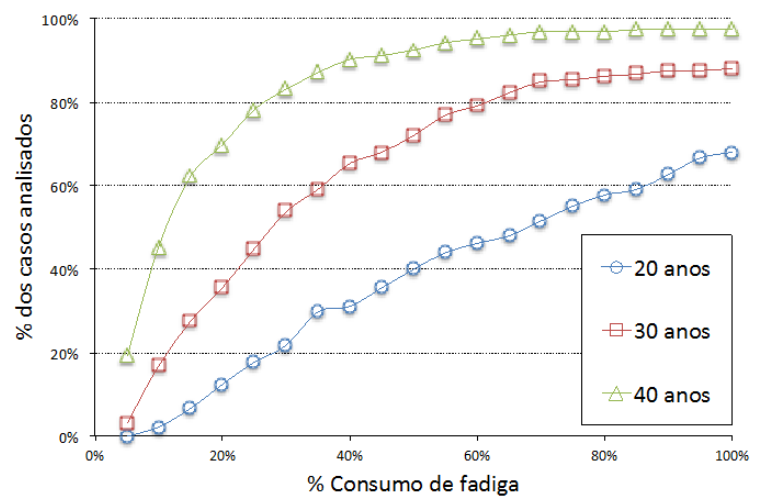

Figura 12. Variação de consumo de fadiga para período de projeto de 20,30 e 40 anos - Caso da BR-101/AL.

\section{CONCLUSÃO}

O presente trabalho apresentou uma avaliação do impacto do período de projeto dos pavimentos no custo dos grandes empreendimentos, considerando as metodologias originalmente utilizadas no dimensionamento. Alguns empreendimentos executados pelo Departamento Nacional de Infraestrutura em Transportes - DNIT possuem serviços auxiliares que podem reduzir o protagonismo do custo de implantação do pavimento, historicamente a parcela mais cara numa obra rodoviária.

Os resultados apresentados mostraram comportamentos distintos da estrutura do pavimento quando analisado o aumento da espessura do revestimento asfáltico em diferentes horizontes de projeto. Concluiu-se que a taxa do aumento da espessura do revestimento asfáltico está relacionada à rigidez da estrutura do pavimento.

Além disso, a variação do período de projeto de pavimentos foi analisada com base no impacto do custo do empreendimento. Aumentando consideravelmente o horizonte de projeto de pavimentos, observou-se que o impacto no custo dos empreendimentos analisados não passou de 4,0\%. Para alguns dos empreendimentos, o impacto não chegou a $1,0 \%$. O reduzido impacto no valor total dos grandes empreendimentos demonstra a prioridade de avaliar os horizontes de projeto de pavimentos com base em análises técnicas. Mais ainda, tais análises devem sem suportadas por estudos mais profundos do ciclo de vida da rodovia, reduzindo, consequentemente, a parcela de importância dada ao custo de implantação do pavimento tendo em vista o pequeno impacto observado quando se aumenta significativamente os horizontes de projeto.

Essa constatação torna-se importante à medida que alguns estudos de viabilidade possam avaliar alternativas de maior robustez, reduzindo a probabilidade de intervenções a curto prazo em pavimentos de grandes empreendimentos. Diante das análises realizadas, constatou-se que o uso de técnicas probabilísticas, tais como a consideração de variáveis de projeto ou até mesmo a existência de erros, reduzem a incidência de rupturas precoces de pavimentos. Sugere-se, por fim e diante dos resultados apresentados, que projetos de pavimentos rígidos tenham horizontes de projeto de 30 anos, enquanto que projetos de pavimentos flexíveis passem a utilizar horizontes de projeto de 20 anos em rodovias federais, visando racionalizar e otimizar serviços de conservação e restauração.

\section{REFERÊNCIAS}

AI (1999). MS-1 - Thickness Design - Highways \& Streets. Asphalt Institute, 9th Edition, $110 \mathrm{p}$.

Borges, W.R., Silva, L.A., Cunha, L.S., Branco, R.M.G.C e Farias, M.M. (2014). GPR Applied to Rigid Pavement from Santos Dumont Airport, RJ. RBGF, Revista Brasileira de Geofísica, 32(2), 225-234.

Ceratti, J. A. P. (1991). Estudo do comportamento à fadiga de solos estabilizados com cimento para utilização em pavimentos. Tese de Doutorado. COPPE, Universidade Federal do Rio de Janeiro.

Codot (2015). Pavement Design Manual. Colorado Department of Transportation, $610 \mathrm{p}$.

DENATRAN (2015). Departamento Nacional de Trânsito, www.denatran.gov.br. Acessado em 15/12/2015.

DNIT (2006). Manual de Pavimentação. Instituto de Pesquisas Rodoviárias, Departamento Nacional de Infraestrutura em Transportes, $277 \mathrm{p}$.

DNIT (2015a). www.dnit.gov.br/planejamento-epesquisa/planejamento/evolucao-da-malha-rodoviaria. Acessado em 15/12/2015.

DNIT (2015b). Reflexos de custos dos empreendimentos em função do incremento da vida útil no dimensionamento dos pavimentos. Relatório de Pesquisa $n^{\circ} 06$, Diretoria de Infraestrutura Rodoviária, 117 p.

FDOT (2015). Flexible and Rigid Pavement Design Manual. Office of Design, Pavement Management Section, Florida Department of Transportation.

HDM (2015). Highway Design Manual. California Department of Transportation. 6th Edition.

Franco, F. A. C. P. (2007). Método de dimensionamento mecanístico-empírico de pavimentos asfálticos-SisPav. Tese de Doutorado, Universidade Federal do Rio de Janeiro, COPPE, 315 p.

Hall, K., Dawood, D., Vanikar, S., Tally, R., Cackler, T., Correa, A. Deem, P., Duit, J., Geary, G., Gisi, A., Hanna, A., Kosmatka, S., Rasmussen, R., TayabjI, S., Voigt, G. (2007). Long-Life Concrete Pavements in Europe and Canada. Federal Highway of Administration Report $n^{\circ}$ FHWA-PL-07-027.

Hidot (2002). Pavement Design Manual. Highways Division, Hawaii Department of Transportation, $75 \mathrm{p}$. 
Heukelom, W., Klomp, A. J. G. (1962). Dynamic testing as a means of controlling pavement during and after construction. Proceedings of the 1st International Conference on the Structural Design of Asphalt Pavement. University of Michigan, Ann Arbor, USA.

Huang, Y. H. (2004). Pavement analysis and design. Segunda edição. Pearson Prentice Hall.

IDOT (2015). Pavement Design. Bureau of Design and Environment Manual. Illinois Department of Transportation, $4366 \mathrm{p}$.

KCC (2001). Road Pavement Design Guide. Kent County Concil, $54 \mathrm{p}$.

MDOT (2012). Pavement Design and Selection. Construction Field Services Division, Michigan Department of

Transportation, $50 \mathrm{p}$

Medina, J., Motta, L. M. G. (2015). Mecânica dos Pavimentos. Editora Interciência, 3a Edição, 640 p.

Santiago, L. S., Soares, J. B. (2015). Contribuições ao desenvolvimento do novo método de dimensionamento de pavimentos asfálticos no Brasil. XXIX Congresso Nacional de Pesquisa em Transporte da ANPET. Ouro Preto, MG.

Santos, C. R. (2011). Dimensionamento e análise do ciclo de vida de pavimentos rodoviários: uma abordagem probabilística. Tese de doutoramento, Universidade de Sâo Paulo (USP). São Paulo.

Silva, L. A. (2014). Uso de Georadar (GPR) e retroanálises de deflexões como suporte a análises probabilísticas de desempenho de pavimentos. Tese de Doutorado, Publicação Departamento de Engenharia Civil, Universidade de Brasília, Brasília, DF, 192p.

SCDOT (2008). Pavement Design Guidelines. Office of Materials and Research Pavement Design Unit, South Caroline Department of Transportation, $47 \mathrm{p}$.

Timm, D. H.; Newcomb, D. E.; Birgisson, B.; Galambos, T. V. (1999) Incorporation of reliability into the Minnesota mechanistic-empirical pavement design method. University of Minnesota. Minneapolis, Minnesota, Estados Unidos.

TXDOT (2011). Pavement Design Guide. Texas Department of Transportation, $428 \mathrm{p}$. 